University of Nebraska - Lincoln

DigitalCommons@University of Nebraska - Lincoln

\title{
$5-2018$
}

\section{Concomitant Crystallization in Propylene/Ethylene Random Copolymer with Strong Flow at Elevated Temperatures}

\author{
Lirong Zheng \\ Tianjin University \\ Lucia Fernandez-Ballester \\ University of Nebraska-Lincoln, lucia.fernandez@unl.edu \\ Gerrit W. M. Peters \\ Eindhoven University of Technology, g.w.m.peters@tue.nl \\ Zhe Ma \\ Tianjin University, zhe.ma@tju.edu.cn
}

Follow this and additional works at: https://digitalcommons.unl.edu/mechengfacpub

Part of the Mechanics of Materials Commons, Nanoscience and Nanotechnology Commons, Other Engineering Science and Materials Commons, and the Other Mechanical Engineering Commons

Zheng, Lirong; Fernandez-Ballester, Lucia; Peters, Gerrit W. M.; and Ma, Zhe, "Concomitant Crystallization in Propylene/Ethylene Random Copolymer with Strong Flow at Elevated Temperatures" (2018).

Mechanical \& Materials Engineering Faculty Publications. 341.

https://digitalcommons.unl.edu/mechengfacpub/341

This Article is brought to you for free and open access by the Mechanical \& Materials Engineering, Department of at DigitalCommons@University of Nebraska - Lincoln. It has been accepted for inclusion in Mechanical \& Materials Engineering Faculty Publications by an authorized administrator of DigitalCommons@University of Nebraska Lincoln. 


\title{
Concomitant Crystallization in Propylene/Ethylene Random Copolymer with Strong Flow at Elevated Temperatures
}

\section{Lirong Zheng, ${ }^{1}$ Lucia Fernandez-Ballester, ${ }^{2}$ Gerrit W. M. Peters, ${ }^{3}$ and Zhe Ma ${ }^{1}$}

1 Tianjin Key Laboratory of Composite and Functional Materials and School of Materials Science and Engineering, Tianjin University, Tianjin 300072, P. R. China

2 Department of Mechanical and Materials Engineering and Nebraska Center for Materials and Nanoscience, University of Nebraska at Lincoln, Lincoln, Nebraska 68588, United States

3 Department of Mechanical Engineering, Eindhoven University of Technology, P.O. Box 513, 5600 MB Eindhoven, The Netherlands

Corresponding author — Zhe Ma, email zhe.ma@tju.edu.cn

ORCIDs

Lirong Zheng: 0000-0001-6803-5048

Lucia Fernandez-Ballester: 0000-0001-6956-5104

Gerrit W. M. Peters: 0000-0001-7208-5128

Zhe Ma: 0000-0003-2458-4197

\begin{abstract}
Flow-induced crystallization of $\alpha$ - and $\gamma$-phases was studied for a propylene/ethylene random copolymer with $3.4 \mathrm{~mol} \%$ ethylene at two high temperatures of 132 and $142{ }^{\circ} \mathrm{C}$ by combining a pressure-driven slit flow device with real-time synchrotron wide-angle $\mathrm{X}$-ray diffraction. At $132{ }^{\circ} \mathrm{C}$, it was found that both $\alpha$ - and $\gamma$-phases were generated at shear stresses ranging from 0.091 to $0.110 \mathrm{MPa}$ and that the $\gamma$-phase always appeared later than the $\alpha$-phase. However, for $142^{\circ} \mathrm{C}$ and the same stresses, only the $\alpha$-phase formed. Only upon cooling the partially crystallized copolymer did the $\gamma$-phase emerge. The lack of $\gamma$-crystals obtained at $142{ }^{\circ} \mathrm{C}$ is opposite to the behavior reported for quiescent crystallization under pressure, for which increasing temperature results in more and even pure $\gamma$-crystals. In the current study, the absence of $\gamma$-phase at $142{ }^{\circ} \mathrm{C}$ is tentatively associated with lack of epitaxial nucleation on $\alpha$-lamellae and to relatively low growth rate of $\gamma$-crystals.
\end{abstract}



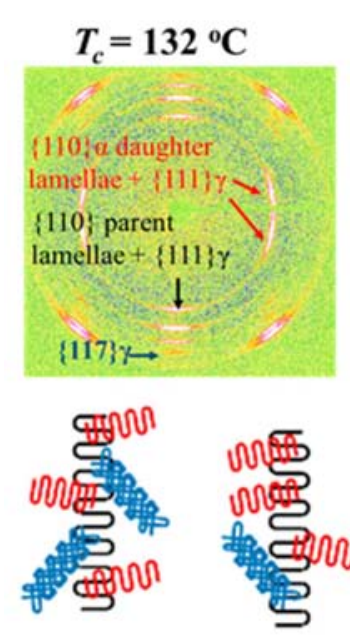
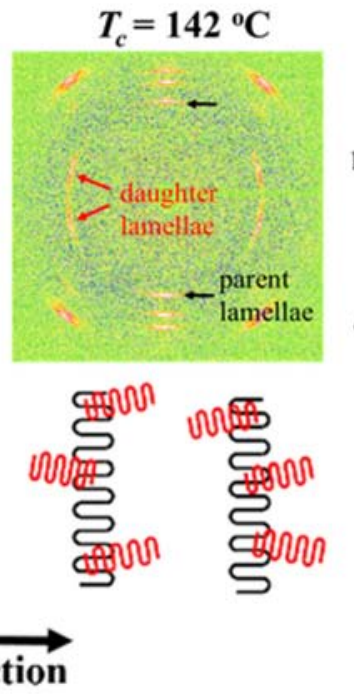
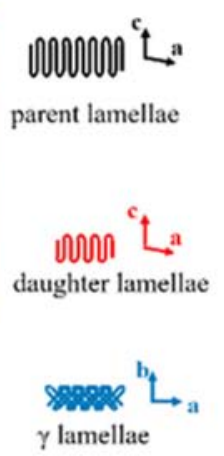

\section{Introduction}

Propylene/ethylene random copolymer (P/E-RACO) is an important semicrystalline material with broad applications including packing, fiber, film, and so on. ${ }^{1}$ The final properties of P/E-RACO are determined by the specific structures formed during crystallization. As a typical polymorphic polymer, P/ERACO can crystallize into a monoclinic $\alpha$-phase, trigonal $\beta$-phase, orthorhombic $\gamma$-phase, and even a mesophase. ${ }^{2-4}$ Among these modifications, $\alpha$-phase is the most common and can be generated from customary solution ${ }^{5}$ and melt crystallizations. ${ }^{6,7}$ Differently, $\gamma$-phase-which has a unique crossed arrangement of chains and exhibits superior modulus and yield strength-is mainly generated with molecular defects ${ }^{8-11}$ or elevated pressure. ${ }^{12-18}$ In P/E-RACO, the presence of ethylene co-units in the main chain significantly enhances formation of $\gamma$-phase. ${ }^{1,8,19}$ Thus, P/E-RACO has improved toughness ${ }^{1}$ and moderate low-temperature impact strength compared with its isotactic polypropylene homopolymer counterpart. ${ }^{20}$ Moreover, an epitaxial relationship exists between the $\gamma$ - and $\alpha$-phases, where $\alpha$-phase grows first and induces the epitaxial growth of $\gamma$-phase. ${ }^{21,22}$ Cavallo et al. ${ }^{23}$ found that $\gamma$-phase can also induce the appearance of $\alpha$-phase via cross-nucleation. In summary, the concomitant crystallization of $\alpha$ - and $\gamma$-phases is a crucial aspect of crystalline structure development in P/E-RA$\mathrm{CO}$, and it is attracting increasing attention from both the academic and industrial communities.

In addition to molecular structure, polymer crystallization also depends strongly on applied external fields. Temperature and flow conditions are the most important parameters during processing, where materials are typically 
molten at elevated temperatures and then experience shear, extensional, or combined flow fields during transport and shaping of the product. Indeed, both temperature and flow greatly influence the process of polymer crystallization. ${ }^{22,24-31}$ For concomitant crystallization of $\alpha$ - and $\gamma$-phases, the temperature dependence of the Gibbs free energy of each phase under atmospheric pressure was calculated by Dimeska et al. ${ }^{6}$ It was found that with increasing temperature the stability superiority of $\alpha$-phase with respect to $\gamma$-phase decreases, and above a critical point, the $\gamma$-phase becomes the stable modification. ${ }^{6}$ Furthermore, it was demonstrated experimentally that under pressure the fraction of $\gamma$-crystals increases as increasing crystallization temperature, and even pure $\gamma$-phase can be obtained. ${ }^{19}$ In conclusion, it seems that elevated temperatures favor the formation of $\gamma$-phase.

Flow can enhance nucleation and induce orientation of polymer chains. ${ }^{28,29,32-41}$ Since such increase in nucleation density can raise the resulting crystallization temperature, the formation of $\gamma$-phase could possibly be facilitated by flow from a thermodynamic point of view. ${ }^{42-44}$ However, the orientation induced by flow may have a different effect. Wang et al. ${ }^{45}$ studied the crystallization of a metallocene-based isotactic polypropylene under shear flow in which the stereoirregularities (i.e., the molecular defects) facilitated the formation of $\gamma$-phase. For this material, the quiescent crystallization at $140{ }^{\circ} \mathrm{C}$ led to a high fraction of up to $66 \%$ of $\gamma$-phase. In contrast, when continuous shear was applied for a long time, the fraction of $\gamma$-phase dropped to $7 \%$. Yang et al. ${ }^{46}$ investigated the shear dependence of $\gamma$-crystal formation in iPP homopolymer. It was found that a high pressure of $100 \mathrm{MPa}$ eventually enhances formation of $\gamma$-phase, which ultimately becomes the dominant modification of the crystallites. When a shear rate of $3.7 \mathrm{~s}^{-1}$ was applied, however, the formation of $\gamma$ crystallites was suppressed. Clearly, flow may on one hand enhance formation of $\gamma$-phase by increasing the crystallization temperature, but it may also impede the formation of $\gamma$-phase due to the substantially distinct crossed segmental arrangement in $\gamma$-phase when compared with flow-induced chain orientation. Given that polymers are typically processed under strong flows and at elevated temperatures, the joint influence of flow and temperature on crystallization of $\alpha$ - and $\gamma$-phases must be understood in order to control structure development and allow rational design of properties.

This work aims at revealing the effects of strong flows and elevated temperatures on flow-induced concomitant crystallization in a propylene/ethylene random copolymer with $3.4 \mathrm{~mol} \%$ ethylene co-units. Experiments were carried out with a pressure-driven flow apparatus capable of applying strong flows with shear stresses up to $0.110 \mathrm{MPa}$. A previously described depthsectioning method was applied to quantitatively separate the effect of flow strength on the resulting flow-induced crystallization process. 


\section{Experimental Section}

\section{Material}

A propylene/ethylene random copolymer, kindly supplied by Borealis, was studied in this work. The detailed molecular and physical properties have been previously reported. ${ }^{1}$ The propylene/ethylene copolymer has a weightaverage molecular mass $M_{\mathrm{w}} \approx 310 \mathrm{~kg} / \mathrm{mol}$ and a molecular weight polydispersity index $M_{\mathrm{w}} / M_{\mathrm{n}} \approx 3.4$. In addition, this propylene/ethylene random copolymer has $3.4 \mathrm{~mol} \%$ ethylene co-units. The melting and crystallization temperatures determined using a heating/cooling rate of $10{ }^{\circ} \mathrm{C} / \mathrm{min}$ are 147 and $105^{\circ} \mathrm{C}$, respectively.

\section{Flow-Induced Crystallization Experiments}

To impose strong shear flows, a pressure-driven flow device designed by Kumaraswamy et al. was employed. ${ }^{47}$ The flow cell has a rectangular slit channel with a width of $6.35 \mathrm{~mm}$ and a thickness of $0.5 \mathrm{~mm}$. The flow channel is $63.5 \mathrm{~mm}$ long and is equipped with two diamond windows suitable for in situ X-ray characterization.

Both the influences of shear stress and temperature on crystallization were studied. For this purpose, we chose two temperatures (142 and 132 ${ }^{\circ} \mathrm{C}$ ) and three (wall) shear stresses $(0.110,0.103$, and $0.091 \mathrm{MPa})$. The shear duration was fixed at $2 \mathrm{~s}$. The flow channel was first filled with polymer melt and annealed at $215^{\circ} \mathrm{C}$ for $5 \mathrm{~min}$ to remove thermal and mechanical histories. Next, the relaxed polymer melt was cooled to the desired crystallization temperature $\left(142\right.$ or $132{ }^{\circ} \mathrm{C}$ ) at a cooling rate of $\sim 5^{\circ} \mathrm{C} / \mathrm{min}$. When the samples were stabilized at the predetermined crystallization temperature, a shear pulse was imposed. After cessation of flow, the sample was held at the same crystallization temperature for $20 \min \left(142\right.$ or $\left.132^{\circ} \mathrm{C}\right)$ and then was cooled down to complete crystallization.

\section{Wide-Angle X-ray Diffraction}

Time-resolved X-ray characterization was employed to monitor the crystallization process during both isothermal and cooling conditions. In-situ synchrotron wide-angle $X$-ray diffraction measurements were carried out at the BM26B (DUBBLE) beamline in the European Synchrotron Radiation Facility (Grenoble, France). ${ }^{48,49}$ The wavelength of the radiation was $1.22 \AA$. A Frelon detector was employed to acquire two-dimensional images with a resolution of $1024 \times 1024$ pixels of $97.6 \mu \mathrm{m} \times 97.6 \mu \mathrm{m}$. The sample-to-detector distance was $157 \mathrm{~mm}$, and the data acquisition time was 15 s per frame. 


\section{Data Analysis}

In a pressure-driven slit flow, the shear stress decreases from a maximum at the wall to zero at the center of the channel. In consequence, the X-ray diffraction patterns contain average information over all layers along the slit thickness direction which are subjected to varying stresses. Recently, a depth-sectioning method was proposed by Fernandez-Ballester et al. ${ }^{35,50}$ to separate the contribution to diffraction arising from flow-induced structures in specific shear layers, i.e., from a specific range of shear stress. The detailed method for data analysis has been previously reported. ${ }^{35,50,51}$ In the present work, experiments were performed at three different wall stresses of 0.110 , 0.103 , and $0.091 \mathrm{MPa}$ and fixed flow duration of $2 \mathrm{~s}$. Therefore, depth-sectioning allows isolating three layers that correspond to depth ranges of $0-16$ $\mu \mathrm{m}(\mathrm{L} 1), 16-43 \mu \mathrm{m}$ (L2), and 43-250 $\mu \mathrm{m}$ (L3) from the wall (see Figure 1).

Different crystal modifications have characteristic crystallographic planes and therefore specific WAXD patterns. ${ }^{52}$ For the X-ray wavelength used in this work, i.e. $1.22 \AA$, the diffraction peaks of the $\alpha$-phase include $\{110\}_{\alpha}$ at $2 \theta=11.1^{\circ},\{040\}_{\alpha}$ at $13.3^{\circ},\{130\}_{\alpha}$ at $14.6^{\circ},\{111\}_{\alpha}$ at $16.6^{\circ}$, and $\{-131\}_{\alpha}$ at $17.2^{\circ}$. Likewise, the $\gamma$-phase exhibits the reflections of $\{111\}_{\gamma}$ at $10.9^{\circ},\{008\}_{\gamma}$ at $13.1^{\circ}$, $\{117\}_{\gamma}$ at $15.8^{\circ},\{202\}_{\gamma}$ at $16.6^{\circ}$, and $\{026\}_{\gamma}$ at $17.1^{\circ}$. Among these WAXD reflections, only the $\{130\}_{\alpha}$ at $14.6^{\circ}$ and the $\{117\}_{\gamma}$ at $15.8^{\circ}$ do not overlap and are therefore employed as the characteristic peaks for the $\alpha$ - and $\gamma$-phase, respectively. The WAXD pattern of amorphous P/E-RACO was measured before shear was applied. The corresponding integrated one-dimensional curve was scaled to fit the amorphous part of crystallizing system and was then subtracted from the diffraction pattern (see Figure 2). Afterward, the amount of $\alpha$ - and $\gamma$-phase fractions was quantified by integrating the area of the corresponding characteristic diffraction peaks in the one-dimensional (1D) WAXD curve, as illustrated in Figure 2.

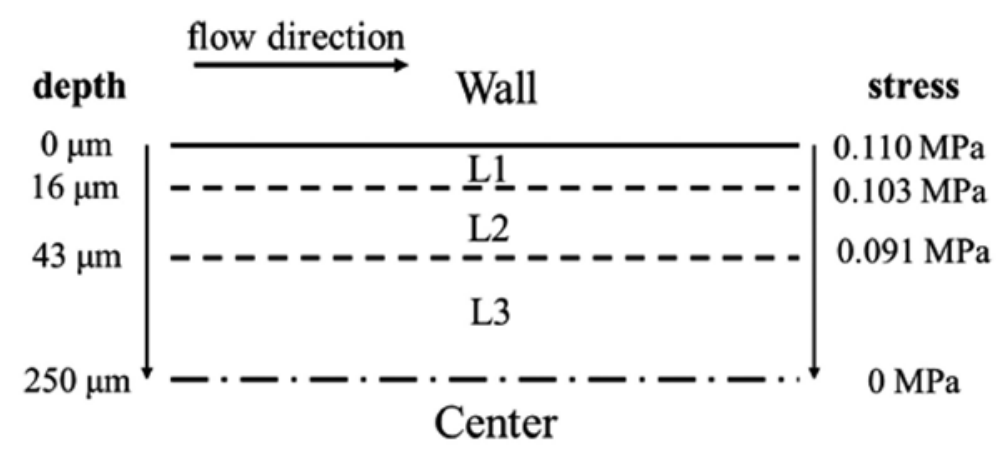

Figure 1. Schematic of the isolated layers and the linear relation between layer depth and the local shear stress. 


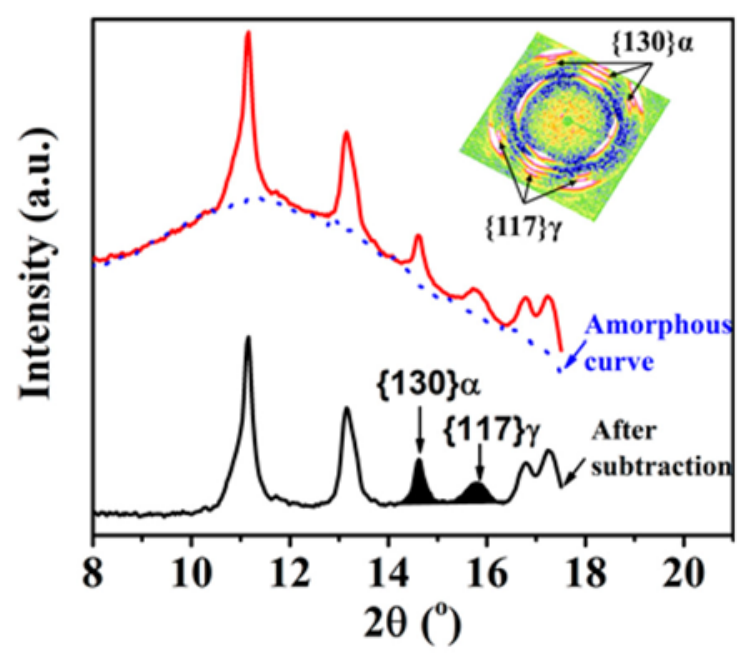

Figure 2. One-dimensional WAXD curves before and after subtracting the amorphous part. The $\{130\}_{\alpha}$ and $\{117\}_{\gamma}$ diffraction peaks are used to quantify the amounts of $\alpha$ - and $\gamma$-phases, respectively.

\section{Results and Discussion}

\section{Flow-Induced Crystallization at $132{ }^{\circ} \mathrm{C}$}

For P/E-RACO, flow-induced crystallization was first studied at $132{ }^{\circ} \mathrm{C}$. Figure $3 a \mathrm{~L} 1-13$ s shows that for a shear stress of $0.110 \mathrm{MPa}$ (layer L1) arc-like

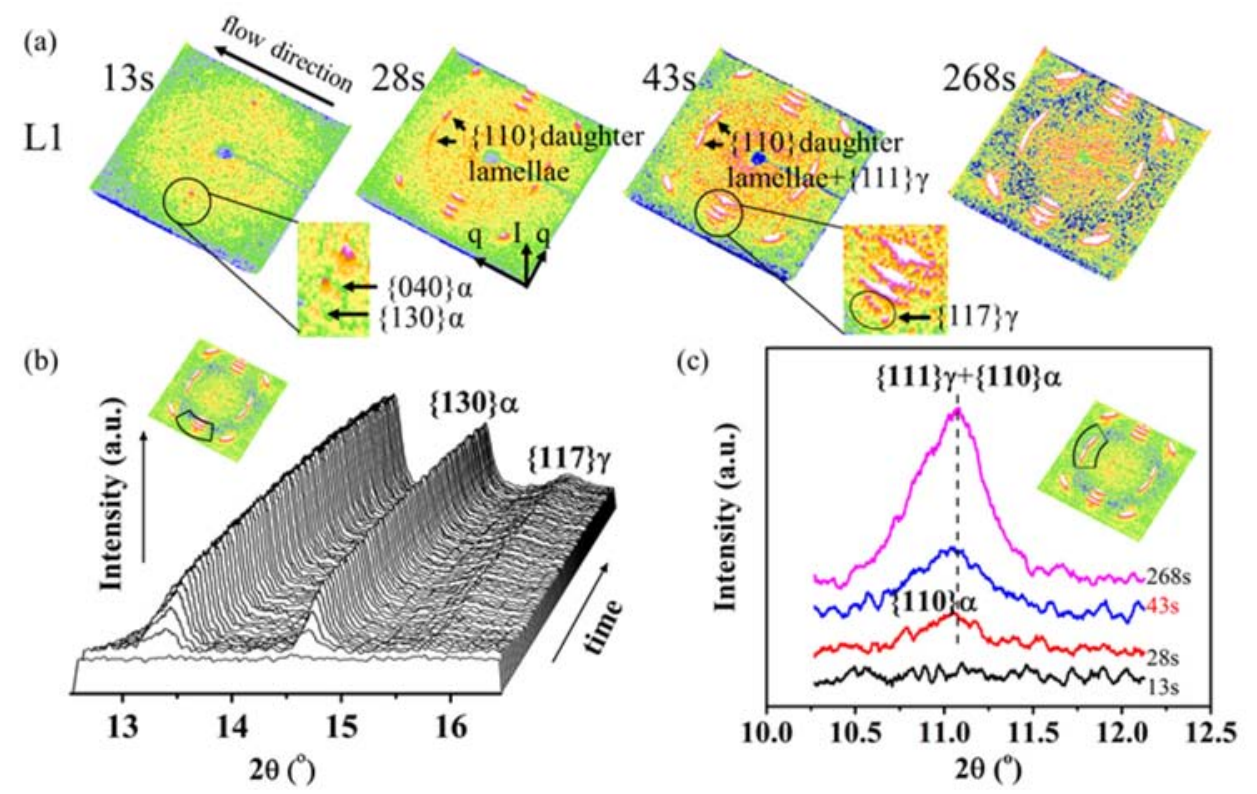

Figure 3. (a) WAXD depth-sectioned patterns of isothermal crystallization in L1 layer at $132{ }^{\circ} \mathrm{C}$. The 1D WAXD curves integrated partially over the (b) equatorial and (c) meridional regions. 
diffraction peaks appear quickly after the shear pulse, which indicate formation of oriented crystallites. Figures $3 b$ and $3 c$ show the corresponding 1D WAXD curves integrated over equatorial and meridional regions, respectively. The characteristic $\{130\}_{\alpha}$ diffraction peaks are observed at $2 \theta$ $=14.6^{\circ}$, meaning that $\alpha$-phase forms in the early stages of crystallization. Furthermore, their narrow azimuthal intensity distribution in the equatorial region shows that these $\alpha$-phase crystallites have $c$-axes oriented along the flow direction.

As isothermal crystallization proceeds in layer L1, new diffraction signals appear in both the equatorial and meridional regions (L1-43s in Figure 3a). The new equatorial peak identified at $2 \theta=15.8^{\circ}$ corresponds to the $\{117\}_{\gamma}$ plane of $\gamma$-phase (see Figure $3 \mathrm{~b}$ ). The simultaneous growth of $\alpha$ and $\gamma$ diffraction peaks reveals that concomitant crystallization of these two phases eventually occurs in the isothermal process at $132^{\circ} \mathrm{C}$. Thus, in the meridional region, the new diffraction peak emerged at $2 \theta=11.1^{\circ}$ belongs to both the $\{110\}_{\alpha}$ planes of $\alpha$-phase daughter lamellae and the $\{111\}_{\gamma}$ planes of oriented $\gamma$-phase. For the $\alpha$-phase, daughter lamellae are nucleated by the $\{010\}_{\alpha}$ lateral surface of parent lamellae. ${ }^{53}$ In layer L1, the observation of daughter lamellae at a later time than parent lamellae is due to the fact that daughter lamellae require sufficient $\{010\}_{\alpha}$ lateral surface of parent lamellae to trigger their crystallization as well as sufficient time to grow for detection. ${ }^{51}$

The shear stress decreases to 0.103 and $0.091 \mathrm{MPa}$ in inner layers $\mathrm{L} 2$ and L3, respectively. As shown in Figure 4, no crystallization was observed immediately after flow in L2 or L3. Afterward, $\alpha$-phase is detected at $28 \mathrm{~s}$ for

(a)

L2

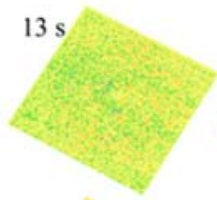

L3

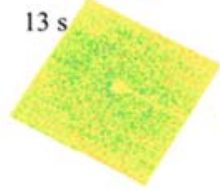

(b) L2
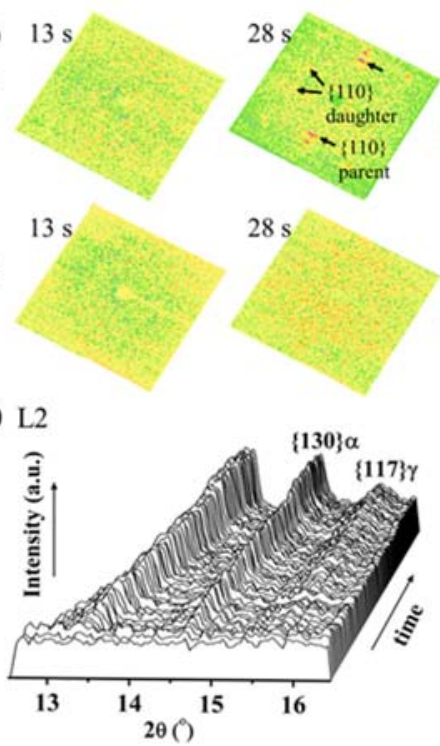
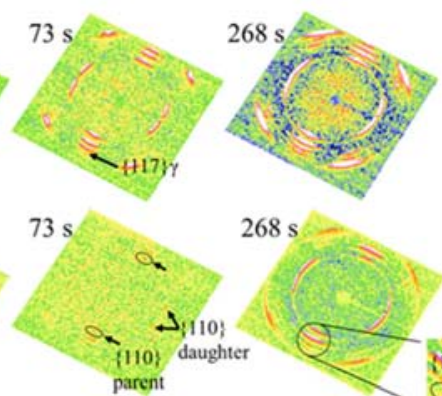

$268 \mathrm{~s}$

(c) $\mathrm{L}$

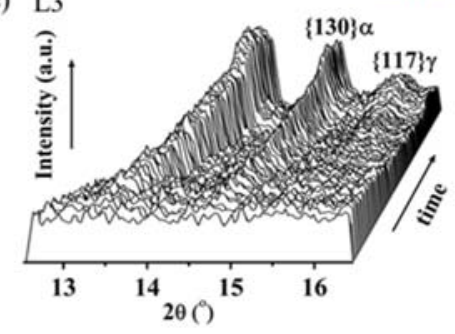

Figure 4. (a) WAXD depth-sectioned patterns of isothermal crystallization at $132^{\circ} \mathrm{C}$ for the L2 and L3 layer. Integrated 1D WAXD curves for the (b) L2 and (c) L3 layer. 
Table 1. Observation Time for Crystallites during Isothermal Crystallization at $132{ }^{\circ} \mathrm{C}$ after Various Flow Conditions

\begin{tabular}{|c|c|c|c|c|}
\hline \multirow[b]{3}{*}{ layer } & \multirow[b]{3}{*}{ shear stress (MPa) } & \multicolumn{3}{|c|}{ observation time (s) } \\
\hline & & \multicolumn{2}{|c|}{$\alpha$-phase } & \multirow[b]{2}{*}{$\gamma$-phase } \\
\hline & & parent lamellae & daughter lamellae & \\
\hline L1 & $0.110-0.103$ & 13 & 28 & 43 \\
\hline L2 & $0.103-0.091$ & 28 & 43 & 238 \\
\hline L3 & $0.091-0$ & 73 & 73 & 268 \\
\hline
\end{tabular}

$\mathrm{L} 2$ and $73 \mathrm{~s}$ for L3. When moving from the L1 to the L3 layer, the decrease in shear stress reduces the number density of flow-induced oriented precursors, and consequently, the overall crystallization kinetics of the $\alpha$-phase becomes slower. As isothermal crystallization proceeds, diffraction peaks corresponding to $\gamma$-phase appear (see Figures $4 b, c)$. This observation demonstrates that concomitant crystallization of $\alpha$ - and $\gamma$-phases also occurs in L2 and L3 layers at $132^{\circ} \mathrm{C}$.

The appearance times of all crystallites are summarized in Table 1. It can be observed that flow accelerates not only the formation of $\alpha$-phase but also that of $\gamma$-phase: indeed, the $\gamma$-phase appears earlier with increasing shear stress. Here, it should be noted that the arc-like diffractions of the $\{117\}_{\gamma}$ reflection are quite narrow even after crystallizing for $20 \mathrm{~min}$, as shown by Figure 5 . This means that the generated $\gamma$-phase sustains a high degree of orientation, which must thus arise from highly oriented nuclei. There are two possible scenarios for nucleating highly oriented $\gamma$-phase: 1) flow induces direct formation of oriented $\gamma$-nuclei in the amorphous melt,

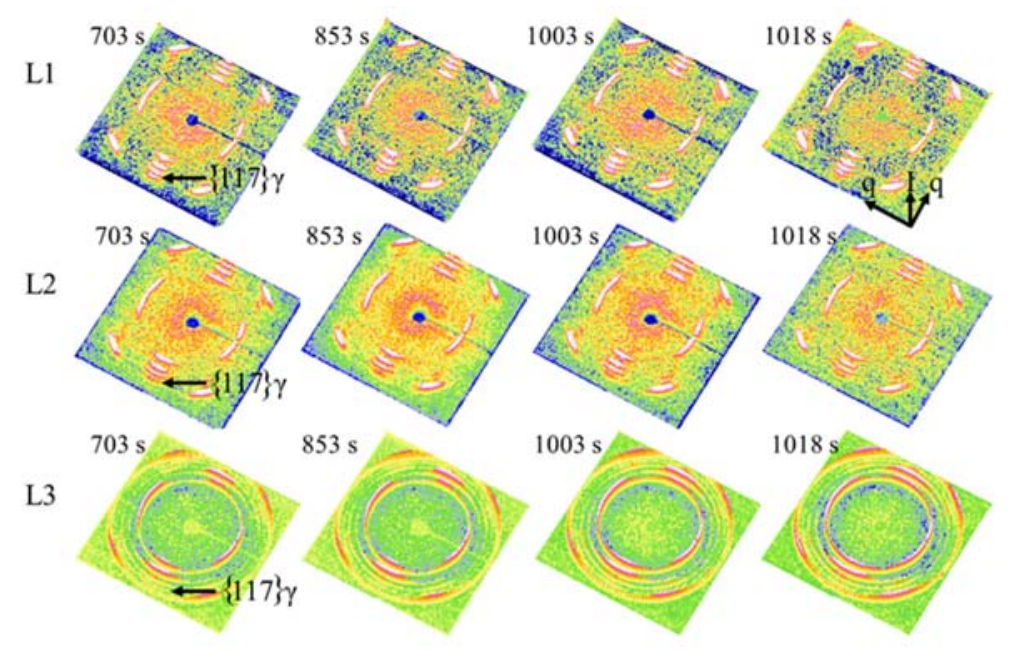

Figure 5. WAXD depth-sectioned patterns of isothermal crystallization at $132{ }^{\circ} \mathrm{C}$ for different shear stresses. 
and 2) the oriented $\alpha$-phase crystallites which grow first provide nucleation sites for $\gamma$-phase. The major difference consists on whether the nuclei for $\gamma$-phase developed from the $\alpha$-phase already present or from the initial amorphous melt.

Under quiescent conditions and high pressure, $\gamma$-nuclei are generated directly from the melt, and pure $\gamma$-phase can be formed. ${ }^{6}$ In contrast, for flowinduced crystallization, $\gamma$-phase is more likely to be nucleated by $\alpha$-phase parent lamellae that have already developed. This is attributed to the unique crossed arrangement of segmental axes in the $\gamma$-phase lattice. In the monoclinic unit cell of $\alpha$-phase, chains packed in the same lamella are all parallel with each other. However, in the orthorhombic $\gamma$-phase, chains are parallel only inside a special bilayer, and there is an angle of $80^{\circ}$ between neighboring bilayers. ${ }^{53}$ In other words, polymer chain segments inside the $\gamma$-phase crystals do not have the same orientation even if they are packed in the same lamellae.

Crossed packing of chain segments in $\gamma$-phase crystals causes differing crystallization behaviors under quiescent and flow conditions. During quiescent crystallization, the growth fronts of lamellae collect chain segments from the isotropic melt and adjust them into the proper orientation for packing into the existing crystalline lattice. In this case, whether chain segments are all parallel is not important. However, when flow of sufficient strength is imposed, it can induce molecular orientation along the flow direction. This flow-induced parallel chain alignment is distinctly different from the "crossed" packing in the $\gamma$-phase, where some chains would have to be rotated by the $80^{\circ}$ angle between neighboring bilayers in order to build up a $\gamma$-crystal. This reorientation process seems unfavorable in flow-induced nucleation, and the imposed flow is more likely to directly form $\alpha$-phase nuclei. In this case, $\alpha$-phase parent lamellae first grow off flow-induced $\alpha$-nuclei, and then $\gamma$-crystals are nucleated by the $\{010\}_{\alpha}$ lateral side surface of $\alpha$-phase parent lamellae. Because the formation of parent lamellae is enhanced as shear stress increases, it is then reasonable that the time of appearance of $\gamma$-crystals is also accelerated for higher shear stress.

For $\alpha$-phase, it is observed that daughter lamellae appear later than parent lamellae for $0.110 \mathrm{MPa}$ (L1) and 0.103 MPa (L2), whereas daughter and parent lamellae appear simultaneously for $0.091 \mathrm{MPa}$ (L3). When comparing both $\alpha$ - and $\gamma$-phases, it is clear that $\gamma$-phase lamellae always appear later than $\alpha$-phase lamellae. Such sequential emergence is consistent with the results of Wang et al. on metallocene-based iPP, ${ }^{45}$ which showed that $\alpha$ - and $\gamma$-phases occur simultaneously when crystallization takes place under quiescent or weak flow conditions (strain $300 \%$ for $30 \mathrm{~s}$ ), whereas the $\gamma$-phase emerged later than the $\alpha$-phase if flow was increased to strain $500 \%$ for $30 \mathrm{~s}$. 


\section{Flow-Induced Crystallization at $142{ }^{\circ} \mathrm{C}$}

The same series of shear stresses were also applied at a higher temperature of $142{ }^{\circ} \mathrm{C}$, which is just below the copolymer nominal melting temperature of $147^{\circ} \mathrm{C}$. Quiescent crystallization hardly occurs at $142{ }^{\circ} \mathrm{C}$ within 20 min (data not shown). Figure 6 shows the 2D WAXD patterns obtained during flow-induced crystallization at $142{ }^{\circ} \mathrm{C}$. Clearly, crystallization kinetics was significantly accelerated by flow imposed. A shear stress of $0.110 \mathrm{MPa}$ was sufficient to induce substantial nucleation of $\alpha$-phase within a short isothermal crystallization of just $13 \mathrm{~s}$, even though $142{ }^{\circ} \mathrm{C}$ is so close to the nominal melting temperature. Then, as shear stress decreases, the time of appearance of $\alpha$-phase becomes longer: for $L 2$ and L3, the first WAXD diffraction signal is observed at 58 and 253 s, respectively.

The results above demonstrate that flows of shear stress between 0.091 and $0.110 \mathrm{MPa}$ are all able to trigger crystallization at elevated temperatures up to $142{ }^{\circ} \mathrm{C}$. An increase in temperature is expected to facilitate the formation of $\gamma$-phase with respect to $\alpha$-phase under quiescent conditions; ${ }^{6}$ however, for fixed flow conditions, $\alpha$ - and $\gamma$-phases were both observed at $132{ }^{\circ} \mathrm{C}$ while the characteristic $\{117\}_{\gamma}$ peak of $\gamma$-phase could not be identified at $142{ }^{\circ} \mathrm{C}$. Indeed, all arc-like WAXD diffraction peaks observed at 142 ${ }^{\circ} \mathrm{C}$ are attributed only to $\alpha$-phase $\{110\}_{\alpha^{\prime}}\{040\}_{\alpha^{\prime}}$ and $\{130\}_{\alpha}$ planes only (see Figure 7), so severe stresses of up to $0.110 \mathrm{MPa}$ did not induce formation of $\gamma$-phase at $142{ }^{\circ} \mathrm{C}$.

All flow strengths applied in the present work are able to stretch polymer chains, as demonstrated by the highly oriented $\alpha$-phase crystallites that formed. The stretched chain segments are favored to orient in the flow direction. However, in order to pack into the crystal lattice of $\gamma$-phase, chain segments would have to rotate by $80^{\circ}$ with respect to neighboring segments within the same bilayer. This means some of the chains already oriented

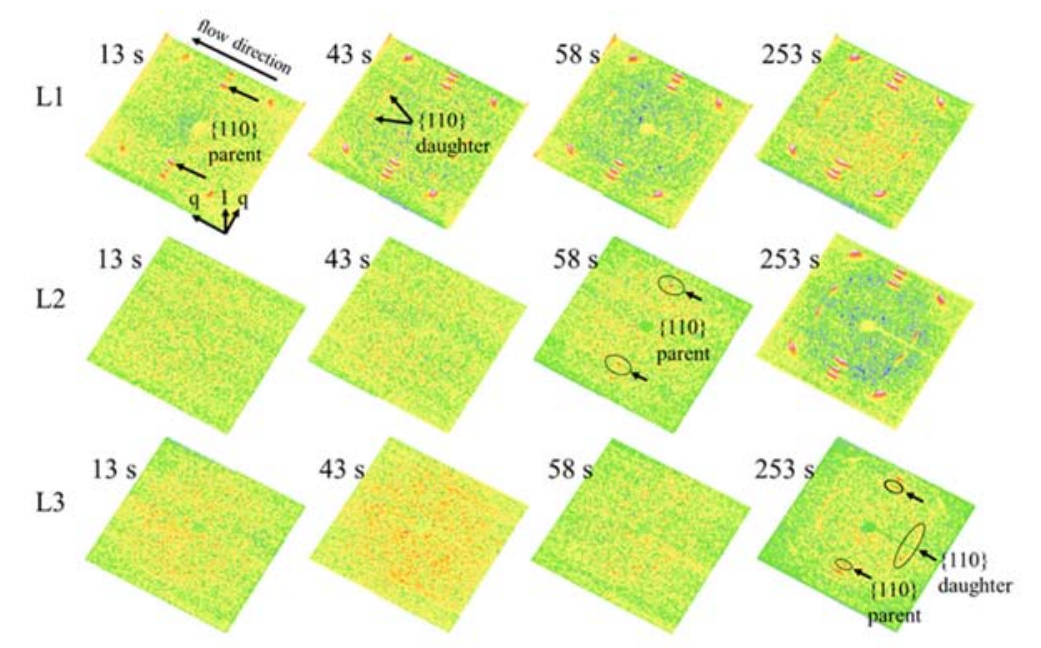

Figure 6. WAXD depth-sectioned patterns of isothermal crystallization at $142{ }^{\circ} \mathrm{C}$. 

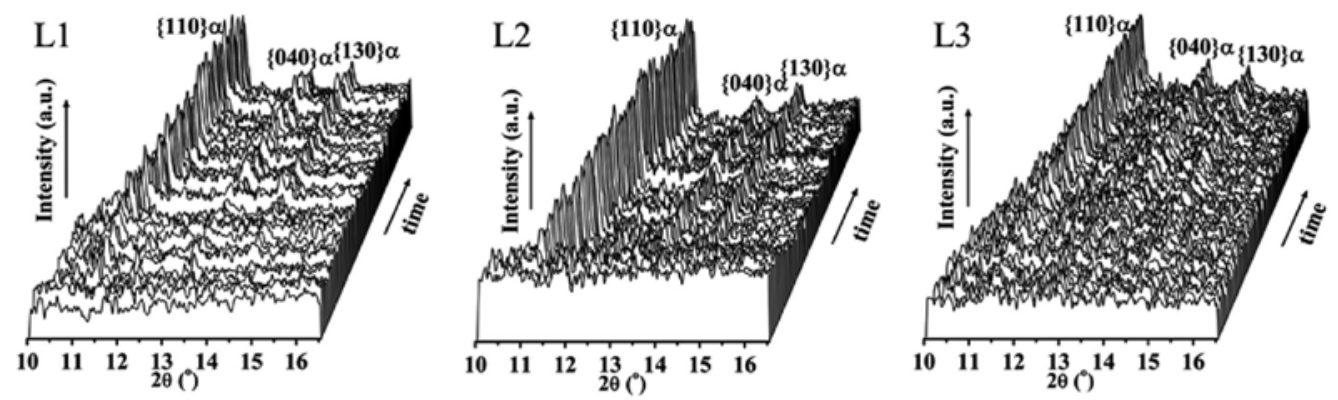

Figure 7. 1D WAXD curves of isothermal crystallization at $142{ }^{\circ} \mathrm{C}$ for different shear stresses.

along the flow direction would be required to rotate to nearly perpendicular direction with respect to flow, which seems unlikely to happen during flow. Thus, the kinetic barrier associated with properly rotating chain segments inhibits the formation of $\gamma$-phase. In contrast, chain segments are parallel with each other within $\alpha$-phase, so the additional rotation is not necessary for $\alpha$-crystallization. Therefore, the formation of $\alpha$-phase crystallites which are oriented is enhanced significantly by flow.

One may think that the absence of $\gamma$-phase at $142{ }^{\circ} \mathrm{C}$ may be caused by the fast kinetics of $\alpha$-phase such that crystallization was completed quickly and $\gamma$-phase had no time to develop. To check whether crystallization was completed by the end of 20 min under isothermal conditions, the evolution of formed $\alpha$-phase is quantified by integrating the diffraction peaks. Figure 8 shows that crystallization at $142{ }^{\circ} \mathrm{C}$ is not completed within $20 \mathrm{~min}$, even after applying a flow pulse with $0.110 \mathrm{MPa}$.

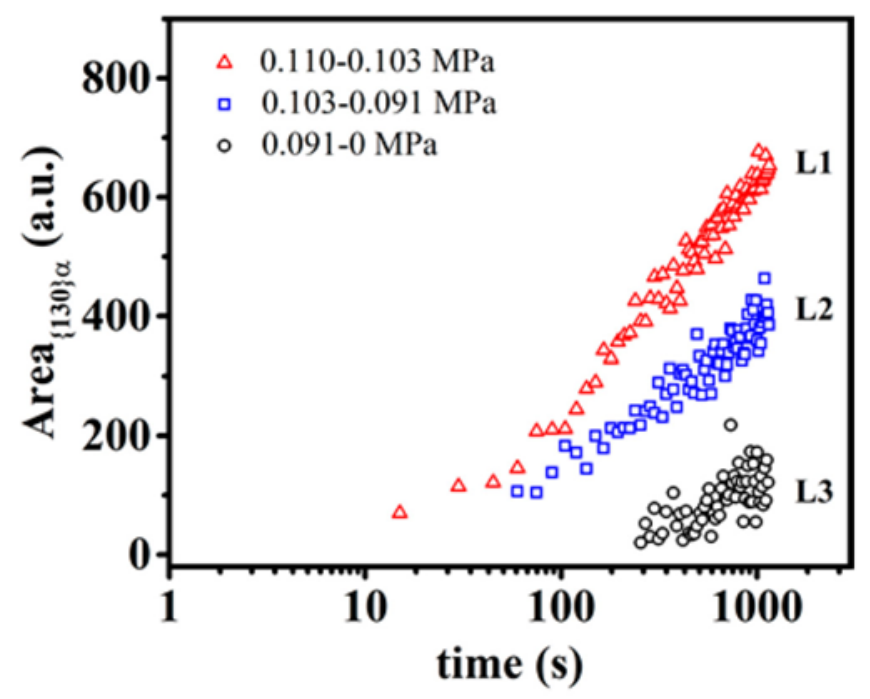

Figure 8. Area evolution of the characteristic $\{130\} \alpha$ diffraction of $\alpha$ - phase parent lamellae during the isothermal process at $142{ }^{\circ} \mathrm{C}$ in various layers with different wall stresses. 
It was unexpected to find that flow-induced crystallization at $142{ }^{\circ} \mathrm{C}$ generates only $\alpha$-phase, since the propylene/ethylene random copolymer has the ability to crystallize into both $\alpha$ - and $\gamma$-phases-as often found in solidified crystallites. ${ }^{4}$ Moreover, the observed meridional $\{110\}_{\alpha}$ diffraction demonstrates formation of daughter lamellae. It is known that daughter lamellae are nucleated by $\{010\}_{\alpha}$ surface, ${ }^{54}$ so the observation of daughter lamellae demonstrates the availability of $\{010\}_{\alpha}$ surface of parent lamellae at 142 ${ }^{\circ} \mathrm{C}$. Lotz et al. have shown that the $\{010\}_{\alpha}$ crystallographic planes of $\alpha$-parent lamellae can also provide nucleation sites for $\gamma$-phase. ${ }^{53}$ Therefore, it is remarkable that $\gamma$-crystals are not generated even though potential nucleation sites are provided. Temperature determines whether concomitant crystallization of $\alpha$ - and $\gamma$-phases occurs. This temperature dependence is different from that previously found for quiescent crystallization under pressure, in which phase stability favors $\gamma$-phase at elevated temperatures. ${ }^{6}$

\section{Cooling Crystallization after Shear-Induced Crystallization for 20 min at $142{ }^{\circ} \mathrm{C}$}

After 20 min of isothermal conditions at $142{ }^{\circ} \mathrm{C}$, the partially crystallized polymer was cooled down. Figure 9 shows representative WAXD images obtained during cooling. The characteristic $\{117\}_{\gamma}$ diffractions of $\gamma$-phase are identified for all three layers. This means that the remaining amorphous molecules can crystallize into $\gamma$-crystals due to the gain of enough undercooling. Figure 9 also demonstrates that $\gamma$-phase crystallites emerged are oriented. These $\gamma$-crystals must result from oriented templates, which are the $\{010\}_{\alpha}$ lateral surface of oriented parent lamellae.

Although flow-induced parent lamellae in the $\alpha$-phase have the capability to nucleate $\gamma$-phase, the appearance of $\gamma$-phase exhibits a strong dependence on temperature. For quiescent crystallization under pressure, Dimeska et al. studied concomitant crystallization of an ethylene/propylene copolymer containing $11.6 \mathrm{~mol} \%$ defect content and found that at pressures above $88 \mathrm{MPa}$ the content of $\gamma$-phase increased with increasing temperature and that even pure $\gamma$-phase could be obtained above $140{ }^{\circ} \mathrm{C} .{ }^{6} \mathrm{On}$ the
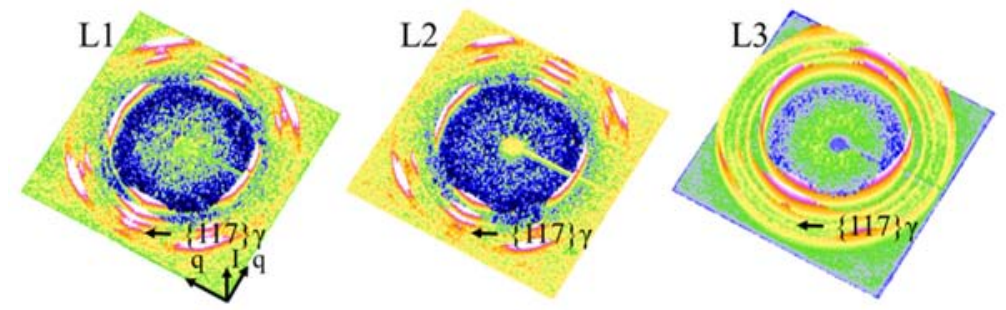

Figure 9. Typical WAXD depth-sectioned patterns obtained at the initial stages of cooling. 
contrary, for flow-induced crystallization studied in the present work, elevating the temperature from 132 to $142{ }^{\circ} \mathrm{C}$ completely suppresses the formation of $\gamma$-phase, although the potential nucleation sites of $\{010\}_{\alpha}$ lateral surface are indeed generated.

A possible explanation for the absence of $\gamma$-phase at $142{ }^{\circ} \mathrm{C}$ may lie in hindered epitaxial nucleation of $\gamma$-crystallites at such temperature. It has been demonstrated by Lotz et al. ${ }^{21,53}$ that nucleation of $\gamma$-phase on $\alpha$-phase is epitaxial, which requires appropriate lattice matching between the initial and induced crystals. In practice, the dimension of the nucleating substrate is often limited, especially for lamellar crystallites that have limited thickness. For substrates with limited dimension, the role of secondary nucleation in epitaxial growth becomes crucial. According to the template model proposed by Greso et al., ${ }^{55}$ secondary nucleation requires that the dimension of the substrate in the matching direction fit or exceed the lamellar thickness of the epitaxially grown crystallites. For example, epitaxial crystallization of high density polyethylene (HDPE) on oriented iPP substrates cannot be observed when the HDPE lamellar thickness is larger than the dimension of the PP substrate in the matching direction (25 vs $23 \mathrm{~nm}$, respectively). ${ }^{56}$ Since a higher temperature requires a larger lamellar thickness for $\gamma$-phase nucleation, increasing the crystallization temperature may preclude the occurrence of epitaxial nucleation, even though the nucleation surface meets the basic requirement of lattice matching. In the present work, epitaxial nucleation of $\gamma$-phase occurs on the $\{010\}_{\alpha}$ surface of the $\alpha$-phase-which is parallel to the $a$ - and $c$-axes-so the substrate dimension must be correlated by the lamellar thickness of parent lamellae. Then, it is possible that the absence of $\gamma$-phase at $142{ }^{\circ} \mathrm{C}$ is associated with a $\alpha$-substrate dimension which is smaller than the required crystal thickness of $\gamma$-crystallites at that temperature.

Another possible reason for the lack of $\gamma$-phase at $142{ }^{\circ} \mathrm{C}$ in flow-induced experiments may be a mismatch between the growth rate of $\alpha$ - and $\gamma$-crystallites. Imposing flow or applying high pressure have different effects on rate of growth of crystallites, and the latter can change the thermodynamic state of both $\alpha$ - and $\gamma$-phases. For example, pressure can vary the specific rate of growth of $\alpha$ - and $\gamma$-phases. An exponential relation was proposed by Pantani et al. ${ }^{57}$ to describe the pressure dependence of growth rate, which is $G_{\max , i}=G_{\text {max }, i}^{\circ} \exp \left(a_{i}\left(p-p_{0}\right)+b_{i}\left(p-p_{0}\right)^{2}\right)$, with $G_{\max , i}^{\circ}$ being the reference growth rate at atmospheric pressure $p_{0}$ and $a_{i}$ and $b_{i}$ being two constants. Furthermore, Van Drongelen et al. ${ }^{58}$ found that the maximum growth rate of the $\gamma$-phase increases with increasing pressure, while that of the $\alpha$-phase remains constant. Therefore, pressure changes the relative growth capability of $\alpha$ - and $\gamma$-phases and favors the crystallization of $\gamma$-phase from a kinetic point of view. Differently, the short-term shearing 
protocol used in this study results in crystallites that grow mainly after application of the shear pulse. Upon cessation of flow, stretched and oriented molecules quickly relax back to a random coil conformation, leading to a growth rate of crystallites similar to that of quiescent conditions. Consequently, the applied flow does not alter the growth rate of crystallites at a given temperature and is not expected to enhance the rate of growth of $\gamma$-phase relative to that of $\alpha$-phase.

Concerning the concomitant crystallization of $\alpha$ - and $\gamma$-phases in the propylene/ethylene random copolymer studied in present work, the strong flows employed in the present work all accelerate the overall crystallization kinetics, whereas the crystallization temperature determines whether $\mathrm{\gamma}$-phase emerges or not.

\section{Conclusions}

The present study combines in situ synchrotron wide-angle X-ray diffraction, pressure-driven slit flow, and the depth sectioning method to investigate flow-induced crystallization of monoclinic $\alpha$-phase and orthorhombic $\gamma$-phase in a propylene/ethylene random copolymer with $3.4 \mathrm{~mol} \%$ ethylene. At $132{ }^{\circ} \mathrm{C}$, both monoclinic $\alpha$-phase and orthorhombic $\gamma$-phase are generated after application of a short shear flow pulse in the range of 0.110-0.091 MPa. As the applied shear stress decreases, highly oriented $\alpha$-phase crystallites appear at increasingly later times. Interestingly, $\gamma$-crystals are always observed later than the highly oriented $\alpha$-phase parent lamellae-although the onset time of $\gamma$-crystals is also accelerated with increasing flow strength. The sequential emergence of parent $\alpha$-lamellae and $\gamma$-crystals may be due to the fact that $\gamma$-crystals require $\{010\}_{\alpha}$ side surface to nucleate and also sufficient time to grow for observation.

It was also found that temperature plays a crucial role in flow-induced crystallization of $\alpha$ - and $\gamma$-phases. At a higher temperature of $142{ }^{\circ} \mathrm{C}$ just $5{ }^{\circ} \mathrm{C}$ below the nominal melting temperature-shear stresses in the range of $0.110-0.091 \mathrm{MPa}$ are sufficient to enhance crystallization. However, at $142{ }^{\circ} \mathrm{C}$, flow-induced crystallization only generates $\alpha$-phase, even though the appearance of daughter lamellae demonstrated that the $\{010\}_{\alpha}$ parent surface-which can provide nucleation sites for $\gamma$-phase-is generated. Only after the partially crystallized polymer was cooled down did oriented $\gamma$-crystals emerge.

Acknowledgments - Z. Ma appreciates the financial support from the National Natural Science Foundation of China $(51633009$, 51573132) and Tianjin Natural 
Science Foundation (16JCQNJC02700). We thank Dr. Markus Gahleitner (Borealis, Austria) for providing the polymer material. NWO (Nederlandse Organisatie voor Wetenschappelijk Onderzoek) and ESRF are acknowledged for granting the beam time. The authors declare no competing financial interests.

\section{References}

1) Gahleitner, M.; Jäskeläinen, P.; Ratajski, E.; Paulik, C.; Reussner, J.; Wolfschwenger, J.; Neißl, W. Propylene-ethylene random copolymers: Comonomer effects on crystallinity and application properties. J. Appl. Polym. Sci. 2005, 95, 1073-1081

2) Housmans, J. W.; Gahleitner, M.; Peters, G. W. M.; Meijer, H. E. H. Structureproperty relations in molded, nucleated isotactic polypropylene. Polymer 2009, 50, 2304-2319.

3) Cavallo, D.; Portale, G.; Balzano, L.; Azzurri, F.; Bras, W.; Peters, G. W.; Alfonso, G. C. Real-Time WAXD Detection of Mesophase Development during Quenching of Propene/Ethylene Copolymers. Macromolecules 2010, 43, 10208-10212.

4) Laihonen, S.; Gedde, U. W.; Werner, P. E.; Martinez-Salazar, J. Crystallization kinetics and morphology of poly(propylene-stat-ethylene) fractions. Polymer 1997, 38, 361-369.

5) Sauer, J. A.; Morrow, D. R.; Richardson, G. C. Morphology of Solution-Grown Polypropylene Crystal Aggregates. J. Appl. Phys. 1965, 36, 3017-3021.

6) Dimeska, A.; Phillips, P. J. High pressure crystallization of random propyleneethylene copolymers: $\alpha-\gamma$ Phase diagram. Polymer 2006, 47, 5445-5456.

7) Mezghani, K.; Phillips, P. J. $\gamma$-Phase in propylene copolymers at atmospheric pressure. Polymer 1995, 36, 2407-2411.

8) De Rosa, C.; Auriemma, F.; Ruiz de Ballesteros, O.; Resconi, L.; Camurati, I. Crystallization Behavior of Isotactic Propylene-Ethylene and PropyleneButene Copolymers: Effect of Comonomers versus Stereodefects on Crystallization Properties of Isotactic Polypropylene. Macromolecules 2007, 40, 6600-6616.

9) Alamo, R. G.; Kim, M.-H.; Galante, M. J.; Isasi, J. R.; Mandelkern, L. Structural and Kinetic Factors Governing the Formation of the $\gamma$ Polymorph of Isotactic Polypropylene. Macromolecules 1999, 32, 4050-4064.

10) Thomann, R.; Wang, C.; Kressler, J.; Mülhaupt, R. On the $\gamma$-Phase of Isotactic Polypropylene. Macromolecules 1996, 29, 8425-8434.

11) Thomann, R.; Semke, H.; Maier, R. D.; Thomann, Y.; Scherble, J.; Mülhaupt, R.; Kressler, J. Influence of stereoirregularities on the formation of the $\gamma$-phase in isotactic polypropene. Polymer 2001, 42, 4597-4603.

12) van Erp, T. B.; Balzano, L.; Peters, G. W. M. Oriented Gamma Phase in Isotactic Polypropylene Homopolymer. ACS Macro Lett. 2012, 1, 618-622.

13) Kardos, J. L.; Christiansen, A. W.; Baer, E. Structure of pressure-crystallized polypropylene. J. Polym. Sci. Part A-2 Polym. Phys. 1966, 4, 777-788.

14) Pae, K. D.; Morrow, D. R.; Sauer, J. A. Interior Morphology of Bulk Polypropylene. Nature 1966, 211, 514-515. 
15) Turner-Jones, A. Development of the $\gamma$-crystal form in random copolymers of propylene and their analysis by dsc and x -ray methods. Polymer 1971, 12, 487-508.

16) Campbell, R. A.; Phillips, P. J.; Lin, J. S. The gamma phase of high-molecularweight polypropylene: 1. Morphological aspects. Polymer 1993, 34, 4809-4816.

17) Mezghani, K.; Phillips, P. J. The $\gamma$-phase of high molecular weight isotactic polypropylene. II: The morphology of the $\gamma$-form crystallized at $200 \mathrm{MPa}$. Polymer 1997, 38, 5725-5733.

18) Mezghani, K.; Phillips, P. J. The $\gamma$-phase of high molecular weight isotactic polypropylene: III. The equilibrium melting point and the phase diagram. Polymer 1998, 39, 3735-3744.

19) Caelers, H. J. M.; Parodi, E.; Cavallo, D.; Peters, G. W. M.; Govaert, L. E. Deformation and failure kinetics of iPP polymorphs. J. Polym. Sci., Part B: Polym. Phys. 2017, 55, 729-747.

20) Lustiger, A.; Marzinsky, C. N.; Mueller, R. R. Spherulite boundary strengthening concept for toughening polypropylene. J. Polym. Sci., Part B: Polym. Phys. 1998, 36, 2047-2056.

21) Lotz, B.; Graff, S.; Straupé, C.; Wittmann, J. C. Single crystals of $\gamma$ phase isotactic polypropylene: combined diffraction and morphological support for a structure with non-parallel chains. Polymer 1991, 32, 2902-2910.

22) Wang, Y.; Zhao, J.; Qu, M.; Guo, J.; Yang, S. G.; Lei, J.; Xu, J. Z.; Chen, Y. H.; $\mathrm{Li}, \mathrm{Z}$. M.; Hsiao, B. S. An unusual promotion of $\gamma$-crystals in metallocenemade isotactic polypropylene from orientational relaxation and favorable temperature window induced by shear. Polymer 2018, 134, 196-203.

23) Cavallo, D.; Galli, F.; Yu, L.; Alfonso, G. C. Cross-Nucleation between Concomitantly Crystallizing $\alpha$ - and $\gamma$-Phases in Polypivalolactone: Secondary Nucleation of One Polymorph on Another. Cryst. Growth Des. 2017, 17, 2639-2645.

24) Lamberti, G. Flow induced crystallisation of polymers. Chem. Soc. Rev. 2014, 43, 2240-2252.

25) Graham, R. S. Modelling flow-induced crystallisation in polymers. Chem. Commun. 2014, 50, 3531-3545.

26) Gebrekrstos, A.; Sharma, M.; Madras, G.; Bose, S. Critical Insights into the Effect of Shear, Shear History, and the Concentration of a Diluent on the Polymorphism in Poly(vinylidene fluoride). Cryst. Growth Des. 2017, 17, 1957-1965.

27) De Rosa, C.; Auriemma, F.; Ruiz de Ballesteros, O.; Dello lacono, S.; De Luca, D.; Resconi, L. Stress-Induced Polymorphic Transformations and Mechanical Properties of Isotactic Propylene-Hexene Copolymers. Cryst. Growth Des. 2009, 9, 165-176.

28) Cui, K.; Ma, Z.; Tian, N.; Su, F.; Liu, D.; Li, L. Multiscale and Multistep Ordering of Flow-Induced Nucleation of Polymers. Chem. Rev. 2018, 118, 1840-1886.

29) Chen, Y.; Bo, X.; Yang, S.; Yang, H.; Lawson, T.; Wu, Z.; Zhang, Q.; Li, Z. Unexpected strength and toughness reinforcement of the injection-molded isotactic polypropylene parts with oriented $\beta$-crystals. Ind. Eng. Chem. Res. 2017, 56, 14252-14262. 
30) Fan, J.; Zhang, Q.; Hu, D.; Feng, J. Nonreversible Enhanced Crystallization of Olefin Block Copolymer Induced by Preshearing. Ind. Eng. Chem. Res. 2016, 55, 3782-3789.

31) Zheng, H.; Wang, B.; Zheng, G.; Wang, Z.; Dai, K.; Liu, C.; Shen, C. Study on Crystallization Kinetics of Partially Melting Polyethylene Aiming To Improve Mechanical Properties. Ind. Eng. Chem. Res. 2014, 53, 6211-6220.

32) Mykhaylyk, O. O.; Chambon, P.; Graham, R. S.; Fairclough, J. P. A.; Olmsted, P. D.; Ryan, A. J. The Specific Work of Flow as a Criterion for Orientation in Polymer Crystallization. Macromolecules 2008, 41, 1901-1904.

33) Hsiao, B. S.; Yang, L.; Somani, R. H.; Avila-Orta, C. A.; Zhu, L. Unexpected ShishKebab structure in a sheared polyethylene melt. Phys. Rev. Lett. 2005, 94, 117802.

34) Kumaraswamy, G.; Issaian, A. M.; Kornfield, J. A. Shear-Enhanced Crystallization in Isotactic Polypropylene. 1. Correspondence between in Situ Rheo-Optics and ex Situ Structure Determination. Macromolecules 1999, 32, 7537-7547.

35) Fernandez-Ballester, L.; Thurman, D. W.; Zhou, W.; Kornfield, J. A. Effect of Long Chains on the Threshold Stresses for Flow- Induced Crystallization in iPP: Shish Kebabs vs Sausages. Macromolecules 2012, 45, 6557-6570.

36) Somani, R. H.; Hsiao, B. S.; Nogales, A.; Fruitwala, H.; Srinivas, S.; Tsou, A. H.; et al. Structure Development during Shear Flow Induced Crystallization of i-PP: In Situ Wide-Angle X-ray Diffraction Study. Macromolecules 2000, 33, 9385-9394.

37) Varga, J.; Karger-Kocsis, J. Rules of supermolecular structure formation in sheared isotactic polypropylene melts. J. Polym. Sci., Part B: Polym. Phys. 1996, 34, 657-670.

38) Roozemond, P. C.; van Erp, T. B.; Peters, G. W. M. Flowinduced crystallization of isotactic polypropylene: Modeling formation of multiple crystal phases and morphologies. Polymer 2016, 89, 69-80.

39) Liu, D.; Tian, N.; Huang, N.; Cui, K.; Wang, Z.; Hu, T.; Yang, H.; Li, X.; Li, L. Extension-Induced Nucleation under Near- Equilibrium Conditions: The Mechanism on the Transition from Point Nucleus to Shish. Macromolecules 2014, 47, 6813-6823.

40) Ju, J.; Wang, Z.; Su, F.; Ji, Y.; Yang, H.; Chang, J.; Ali, S.; Li, X.; Li, L. Extensional Flow-Induced Dynamic Phase Transitions in Isotactic Polypropylene. Macromol. Rapid Commun. 2016, 37, 1441-1445.

41) Ma, Z.; Balzano, L.; Portale, G.; Peters, G. W. M. Flow induced crystallization in isotactic polypropylene during and after flow. Polymer 2014, 55, 6140-6151.

42) Pantani, R.; Coccorullo, I.; Volpe, V.; Titomanlio, G. Shear-Induced Nucleation and Growth in Isotactic Polypropylene. Macromolecules 2010, 43, 9030-9038.

43) Housmans, J. W.; Steenbakkers, R. J. A.; Roozemond, P. C.; Peters, G. W. M.; Meijer, H. E. H. Saturation of Pointlike Nuclei and the Transition to Oriented Structures in Flow-Induced Crystallization of Isotactic Polypropylene. Macromolecules 2009, 42, 5728-5740.

44) Janeschitz-Kriegl, H. Conditions of nucleation in crystallizable polymers: reconnaissance of positions - a critical evaluation. Colloid Polym. Sci. 1997, $275,1121-1135$. 
45) Wang, Y.; Chen, C.; Xu, J. Z.; Lei, J.; Mao, Y.; Li, Z. M.; Hsiao, B. S. Suppressing of $\gamma$-crystal formation in metallocene-based isotactic polypropylene during isothermal crystallization under shear flow. J. Phys. Chem. B 2012, 116, 5056-5063.

46) Yang, S. G.; Zhang, Z.; Zhang, L. Q.; Zhou, D.; Wang, Y.; Lei, J.; Li, L.; Li, Z. M. Unexpected Shear Dependence of Pressure-Induced $\gamma$-Crystals in Isotactic Polypropylene. Polym. Chem. 2015, 6, 4588-4596.

47) Kumaraswamy, G.; Verma, R. K.; Kornfield, J. A. Novel flow apparatus for investigating shear-enhanced crystallization and structure development in semicrystalline polymers. Rev. Sci. Instrum. 1999, 70, 2097-2104.

48) Bras, W.; Dolbnya, I. P.; Detollenaere, D.; van Tol, R.; Malfois, M.; Greaves, G. N.; Ryan, A. J.; Heeley, E. Recent experiments on a small-angle/wide-angle X-ray scattering beam line at the ESRF. J. Appl. Crystallogr. 2003, 36, 791-794.

49) Portale, G.; Cavallo, D.; Alfonso, G. C.; Hermida-Merino, D.; van Drongelen, M.; Balzano, L.; Peters, G. W. M.; Goossens, J. G. P.; Bras, W. Polymer crystallization studies under processing-relevant conditions at the SAXS/WAXS DUBBLE beamline at the ESRF. J. Appl. Crystallogr. 2013, 46, 1681-1689.

50) Fernandez-Ballester, L.; Thurman, D. W.; Kornfield, J. A. Realtime depth sectioning: Isolating the effect of stress on structure development in pressure-driven flow. J. Rheol. 2009, 53, 1229-1254.

51) Ma, Z.; Fernandez-Ballester, L.; Cavallo, D.; Gough, T.; Peters, G. W. M. High-Stress Shear-Induced Crystallization in Isotactic Polypropylene and Propylene/Ethylene Random Copolymers. Macromolecules 2013, 46, 2671-2680.

52) Valdo Meille, S.; Brückner, S. Non-parallel chains in crystalline $\gamma$-isotactic polypropylene. Nature 1989, 340, 455-457.

53) Lotz, B.; Graff, S.; Wittmann, J. C. Crystal morphology of the $\gamma$ (triclinic) phase of isotactic polypropylene and its relation to the $\alpha$ phase. J. Polym. Sci., Part B: Polym. Phys. 1986, 24, 2017-2032.

54) Lotz, B.; Wittmann, J. C. The molecular origin of lamellar branching in the $\alpha$ (monoclinic) form of isotactic polypropylene. J. Polym. Sci., Part B: Polym. Phys. 1986, 24, 1541-1558.

55) Greso, A. J.; Phillips, P. J. The role of secondary nucleation in epitaxial growth: the template model. Polymer 1994, 35, 3373-3376.

56) Yan, S.; Yang, D.; Petermann, J. Controlling factors for the occurrence of heteroepitaxy of polyethylene on highly oriented isotactic polypropylene. Polymer 1998, 39, 4569-4578.

57) Pantani, R.; Coccorullo, I.; Speranza, V.; Titomanlio, G. Morphology evolution during injection molding: Effect of packing pressure. Polymer 2007, 48, 2778-2790.

58) van Drongelen, M.; van Erp, T. B.; Peters, G. W. M. Quantification of nonisothermal, multi-phase crystallization of isotactic polypropylene: The influence of cooling rate and pressure. Polymer 2012, 53, 4758-4769. 